\title{
Service user experience of the Norfolk youth service
}

David Heavens $^{1 *}$, Joanne Hodgekins ${ }^{2}$, Rebecca Lower ${ }^{1}$, Joanne Spauls $^{1}$, Benjamin Carroll ${ }^{1}$, Brioney Gee ${ }^{1}$, Timothy Clarke ${ }^{1}$ and Jon Wilson $^{1,2}$

${ }^{1}$ Child, Family and Young Person service, Norfolk and Suffolk NHS Foundation Trust, Norfolk, UK

${ }^{2}$ Department of Clinical Psychology, Norwich Medical School, University of East Anglia, Norfolk, UK

*Corresponding author: Dr David Heavens, e-mail: dave.heavens@nsft.nhs.uk 


\begin{abstract}
Purpose

There is an international drive to improve mental health services for young people. This study investigates service user experience of a youth mental health service in Norfolk, UK. In addition to suggesting improvements to this service, recommendations are made for the development of youth mental health services in general.
\end{abstract}

\title{
Design/methodology/approach
}

A mixed-methods approach was used. Quantitative data from satisfaction questionnaires were analysed using descriptive statistics and compared between two time points. A semistructured interview was used to generate qualitative data. Thematic analysis was used to identify themes in the interview transcripts and triangulation was used to synthesise quantitative and qualitative data.

\section{Findings}

Service users appeared satisfied with the service. Significant improvements in satisfaction were found between two time points. Qualitative analysis identified three main themes that were important to service users including support, information and personhood.

\section{Practical implications}

Recommendations for the development of youth mental health services are provided. Although these are based on findings from the Norfolk youth service they are likely to apply to other mental health services for young people. 


\section{Originality/value}

Mental health care for young people requires significant improvement. The Norfolk youth service is one of the first services of its kind in the UK. The findings from this study might be helpful to consider in the development of youth mental health services across the world.

Key words:

Adolescent; youth; young people; mental health; community mental health; service user

Paper type

Research paper 


\section{Introduction}

Approximately $50 \%$ of mental health difficulties emerge by the mid-teens and $75 \%$ occur by the mid-20s (Kessler et al., 2007). This is a vulnerable period that involves important developmental milestones (Gorter et al., 2014) and providing adequate care during this time is vital (Simmons et al., 2014). Despite this, mental health provision often involves a move from child and adolescent to adult services at 18 years of age (Broad et al., 2017), leading to inadequate support when it is needed most (McGorry, 2007). This may lead to poor outcomes (Gibb et al., 2010).

The current structure of mental health care for young people is inadequate and change is needed (McGorry et al., 2013). In recent years there has been a drive to reform mental health provision for children and young people, based on the International Declaration on Youth Mental Health (Coughlan et al., 2013). In the UK, policy and guidance has placed emphasis on transforming mental health services for young people (Department of Health and Department of Education, 2017; NHS England, 2015; NHS England, 2019). Several youth mental health models, offering support up to 25 years (rather than the traditional transition from child and adolescent to adult services at 18 years), have been established in Australia, Ireland and Birmingham, UK (Illback and Bates, 2001; McGorry et al., 2013; Rickwood et al., 2015). By focusing support when it is needed, this model has the potential to improve outcomes and reduce transition rates to adult services (McGorry et al., 2013).

A youth mental health service in Norfolk, UK, was developed in 2012 to provide support to young people aged 14-25 years. This offers community-based assessment and intervention, with focus on social recovery, outreach liaison and support for partner organisations. An intensive crisis approach is used to prevent referral to inpatient care (see Wilson et al., 2017 for further details). In 2014 a Children and Young People's Mental Health and Wellbeing Taskforce was established in the UK. As one of the first youth mental health 
services in the UK, the Norfolk youth service is highlighted as a model of service delivery in the taskforce's guidance (Department of Health, 2015).

The youth mental health movement emphasises the need to involve young people in shaping services (McGorry et al., 2019). In support, the benefit of service users having a voice and sharing their preferences has been emphasised (McGorry et al., 2013). This is in line with recommendations that those accessing services are best placed to suggest service improvements (Institute for Innovation and Improvement, 2010). Service evaluation is particularly important in understanding the best models of service implementation (Hetrick et al., 2017) so that better outcomes can be achieved (Coughlan et al., 2013).

Several studies have investigated young people's experience of services. In a review of young people's views of UK mental health services, Plaistow et al. (2014) found that that stigma, lack of information or access to services, medicalisation of difficulties, or a lack of continuity in care were important factors. They also highlight the importance of staff having good qualities and skills and service users being encouraged to be self-reliant. Lavis and Hewson (2011) suggest that young people want services that offer flexibility, support, choice, accessibility, friendly and welcoming environments, good staff attitudes, communication and being treated with respect. Furthermore, young people have suggested they need services that offer information and choice and include staff who are approachable, genuine, understanding and value their input (Collins et al., 2017).

Although the Norfolk youth service involved service users in its original design (Collins et al., 2017), service satisfaction and experience have not been formally investigated. This has been recommended as an important research target in previous work (Wilson et al., 2017). The current study aims to investigate whether service users are satisfied with the Norfolk youth service and what factors are important in the service users' experience of the service. The study also aims to investigate change in satisfaction over time. 
Despite local differences the framework and principles of youth mental health services are likely to be similar nationally and internationally. It is suggested that different countries should share practice and demonstrate what works well (Rickwood et al., 2019), contributing to a revolution in youth mental health care (McGorry et al., 2019). In the UK transformation policy suggests a 'trailblazer' approach to service evaluation, so that ideas and resources can be shared to support service expansion (Department of Health and Department of Education, 2017). It is therefore hoped that the findings and recommendations from this study will be useful for other youth mental health services across the world.

\section{Method}

\subsection{Design}

A mixed methods design was used focusing on the collection, analysis and merging of quantitative and qualitative data (Palinkas, 2014). This is in line with other studies investigating young people's experiences of mental health services (Plaistow et al., 2014) and provided more information than if quantitative or qualitative approaches had been used alone (Creswell and Plano Clark, 2011). Quantitative data were used to obtain breadth and qualitative methods were used for depth and exploration (Tashakkori and Teddlie, 2003). Quantitative data measuring service user satisfaction were available from the service via routine data collection. Data were compared between two samples at different time points to investigate change over time. Qualitative data, collected at the same time as the first set of quantitative data, were used to conduct a detailed exploration of individual experience (Yardley, 2000).

\subsection{Participants}

Anonymised data were obtained from a convenience sample of 125 service users between February 2013 and June 2015 (time point one) and compared to data from another 
sample of 125 service users between February 2016 and August 2018 (time point two). These data were available from the service following voluntary and anonymous completion of a questionnaire that is provided to all service users. The 125 participants at time point one were aged between $14-25$ years. The mean age was 18 years $(\mathrm{SD}=3.11)$ and they were $72 \%$ female. One-hundred and eighteen participants were White-British, two were Black Caribbean and one was Indian-Asian British. Four participants did not disclose their ethnicity. At time point two, the 125 participants were aged between $14-26$ years ${ }^{[1]}$, with a mean age of 19 years $(\mathrm{SD}=3.56)$ and $69 \%$ female (seven participants did not disclose their gender). Data on ethnicity were not collected for this sample.

Qualitative data were obtained from six service users, recruited through opportunity sampling. Participants were identified by case managers and consent was gained for them to be contacted via telephone to arrange an appointment. Three of the six participants were actively engaging with the service and three participants were not. This approach was adopted to obtain balanced views. Those not engaging with the service were defined as those who had been offered support but were not consistently in contact or attending appointments. The six participants were aged between 15 and 23 years $($ Mean $=20 ; S D=3.44)$. Further demographic information is provided in Table 1.

[Table 1 here]

\subsection{Measures}

\subsubsection{Experience of Service Questionnaire (ESQ)}

The 12-item ESQ was designed by the Commission for Health Improvement (AttrideSterling, 2002) to measure satisfaction within child and adolescent mental health services. During development of the Norfolk youth service an adapted version was created to improve 
suitability for the youth population. Additional questions are included that refer to religious and cultural needs, involvement in decisions regarding care, availability of information and support for family members and during crisis. This version includes 13 items, each scored on a five-point Likert scale from 'Strongly Agree' to 'Strongly disagree'. All items are positively rated, with higher agreement suggesting greater satisfaction. The additional item asks whether service users would recommend the service to a family member or friend, rated on a 10-point scale from 'Highly likely' to 'Very unlikely'.

In order to improve face validity the ESQ was further adapted in 2016, with rewording of some questions and removal of others. This version includes eight items which are scored on a five-point Likert scale from 'Strongly agree' to 'Strongly disagree', with six of these eight items corresponding directly to the ESQ originally adapted by the Norfolk youth service. Only scores for the six items that remained unchanged were used for statistical analysis. The item measuring how likely a service user would recommend the service to a family member or friend remains; however, this was adapted to a six-point Likert scale ranging from 'Extremely likely' to 'Extremely unlikely'.

\subsubsection{Semi-structured interview}

A semi-structured interview schedule was designed in collaboration with the Norfolk youth service council. The council is a group of service user representatives who have previously had clinical contact with the service. Based on their recommendations the following interview categories were included: accessing the service; availability of information; relationships with staff members; suitability of treatment; and working with other people in the young person's life (e.g. family, school, work). The semi-structured interview was completed face-to-face with the first author (DH). The participants were not known to the interviewer, reducing the potential for bias. All interviews were recorded and transcribed verbatim. 


\subsection{Data analysis}

Descriptive statistics were calculated for the items on the ESQ at both time points. As a secondary analysis, between group comparisons were made between the satisfaction scores at both time points using SPSS (SPSS Inc, Chicago, IL, USA). As noted above only scores for the six items that remained unchanged in two adaptions of the ESQ were compared. The distribution of scores were highly skewed and could not be successfully transformed to meet the assumption of normality, so the non-parametric Mann Whitney U test was used to compare scores. A Bonferroni correction was made to counteract the problem of multiple comparisons, with a $p$ value of 0.008 .

Thematic analysis (TA) was used to analyse the qualitative data in line with the sixphase methodology outlined by Braun and Clarke (2006). TA identifies, analyses and reports patterns ('themes') from data. TA was chosen as it is an accessible and flexible approach to data analysis. A realist, semantic approach was adopted, with a focus on identifying themes at the surface-level (Braun \& Clarke, 2006). The data were coded and analysed by the first author (DH) using NVivo 11. Three transcripts, selected randomly, were analysed by the second author $(\mathrm{JH})$ for relevant themes. These corresponded to those identified by DH. Prior to analysis transcripts were sent to the participants to check for accuracy.

Data for the study were analysed in the order noted above. Following this triangulation was used to synthesise the quantitative and qualitative data (this was conducted by $\mathrm{DH})$. Triangulation takes information from different sources and assesses convergence between them. Through this process alternative constructions can be considered reducing misinterpretation and increasing the validity of the analysis (Stiles, 1993). In the current study the quantitative scores from the items of the ESQ were compared to the themes identified in the qualitative data. This highlighted similarities and differences between the data which were used to draw conclusions about service user experience. 


\section{Results}

\subsection{Quantitative analysis}

Quantitative data for the ESQ are displayed in Tables 2 and 3.

[Tables 2 and 3 here]

For all items at both time points, 'Agreed' or 'Strongly agreed' were the most commonly selected responses, suggesting a high degree of satisfaction. Furthermore, on items used on both versions of the ESQ there was an improvement in satisfaction scores between time points one and two. For the secondary analysis, all six items analysed demonstrated significant improvements in responses on the ESQ from time point one to time point two (see Table 4). Even when adjusting for multiple comparisons all analyses remained significant. Ninety-one (73\%) respondents rated 'Likely' to 'Highly likely' that they would recommend the Norfolk youth service to a friend or family member at time point one, compared to 97 respondents $(83 \%)$ rating 'Extremely likely' or 'Likely' at time point two.

[Table 4 here]

\subsection{Qualitative analysis}

The qualitative analysis identified three main themes, each with three sub-themes (See Figure 1). The themes are summarised below.

[Figure 1 here] 


\subsubsection{Theme 1: Support}

Most participants referred to the importance of support in their experience with the service. The participants highlighted the importance of staff being proactive and available, as well as offering moral support. Some participants suggested that the quantity of support from staff was important to them.

"I found them to be...supportive." (P4)

"It's good that they are always kind of checking that I'm able to be on top of it all" (P3)

"She kinda gave me moral support and stuff but I didn't get much help from her" (P1)

Some participants also highlighted the importance of support from peers, either in person or online. Participants suggested that greater connection with other service users could be helpful, either through discussion or doing something practical.

"You could have a Facebook page... all the time they've got someone on there you can talk to" (P1)

"You can get people doing stuff...in a supportive atmosphere" (P2)

"Just as an idea a drop-in two-hour session... where these people act like a human library...you're a human book...” (P4). 
The participants noted the importance of receiving support with education, with a specific focus on exams and coursework. The importance of communication with teachers and other educational professionals was emphasised, with some participants valuing advice and others wanting more direct intervention. Participants also noted the importance of support with occupation. Emphasis was placed on receiving support in building confidence so that employment can be achieved. Overall participants suggested that they had experienced an absence of support in this area.

"She did offer to come along with me to several events and exams and stuff. She did also suggest how I could approach teachers" (P1)

“They [the staff] would explain why my coursework was late again... if needed they'd come to meetings as an advocate or just as more moral support" (P2)

"Working is probably the most terrifying thing about having this illness...maybe some help on this because I'd really like to go to work" (P4)

“I think the one area that they've not done so well in is occupational functioning, independent living that kind of thing." (P2)

\subsubsection{Theme 2: Information}

Participants discussed the importance of being provided with information. They suggested that communication about the service could be helpful, either through a website or leaflet. Having awareness of the youth service and its purpose appeared to be particularly important. 
"I would recommend a friendly website or like a friendly leaflet or something...so that it doesn't seem like this secluded like secret place" (P1)

"Perhaps a leaflet briefly explaining exactly who the youth service is and the services they offer or whatever might be useful" (P2)

"I would have just liked some sort of correspondence in the post" (P3).

Information about diagnosis also appeared important, with an emphasis on the need for identification, transparency and communication. Participants also suggested that it is important to have diagnoses explained. Overall participants appeared keen to be provided with a diagnosis.

"Whether they turn it into an official diagnosis or not...I'd also like to see more semistructured or fully-structured interviews" (P2)

If you don't have a diagnosis...then that's even worse...that's like telling someone you're really sick but we're not going to explain to you why" (P4)

"Sometimes people want a sort of checkbox...I might be bipolar, I'm not sure because no one has actually told me" (P5)

Receiving information about available treatments also appeared helpful to participants. Again, they appeared keen to receive these in the form of leaflets. It was also noted that it was helpful to receive leaflets about available treatments. 
"I think leaflets should be given out about medication" (P2)

"I was given more than enough leaflets to read I believe" (P5)

"I think she gave me a couple of leaflets to read about...I did find a couple of them really helpful" (P6)

\subsubsection{Theme 3: Personhood}

Several participants discussed the importance of being treated as an individual. Understanding from staff was important to some. Having knowledge about the service users' situation and how to respond to this appeared to be particularly important. The need to gain a broad overview of the person's life and situation was also suggested.

"Just the understanding...I think it's important for the staff to know how to approach someone with anxiety" (P1)

'I'd like to see people [staff]...be given a fairly comprehensive view of what's going on in somebody's life" (P2)

“I feel like in various ways you are a piece of paper that isn't listened to or very much understood" (P4)

Participants also noted the importance of respect. They emphasised a wish for staff members' to be respectful in their interactions and maintain confidentiality. The level of 
respect received appeared important to some. Participants also appeared to want staff to show respect by ensuring that their wishes are accounted for.

"She [staff member] was just treating me with the right amount of respect" (P1)

"I like my family kept as far out of my medical details as possible...and they [the service] respected that wish" (P5)

"Yeah, she treats me with a lot of respect." (P6)

Some participants referenced the need to be offered choice. For most participants this appeared to be related to the type of treatment received. More specifically, not feeling obliged or forced to receive certain treatments appeared important.

"I didn't tell my mother anything...but that was my choice." (P2)

"No obligation to do anything and that was very strongly put across, that it's very much my choice" (P3)

"They gave me the choice...they gave me the booklet and I went away and had a look" (P4)

\section{Discussion}

The quantitative data suggest that overall, service users are satisfied with the Norfolk youth service. At both time points 'Agreed and 'Strongly agreed' were the most commonly 
selected responses on the ESQ. A significant improvement was observed in satisfaction scores between the time points. In addition, most participants at both time points reported that they would recommend the service to family and friends. A number of themes and subthemes were developed from the qualitative data, highlighting factors important to service users in their experience of the service.

The qualitative analysis highlights the importance of support from staff, with an emphasis on staff being proactive and available. Data from the ESQ show that at time point one, $77 \%$ of participants felt that the people they see at the service work together to help them (Item 7). During the interviews participants also noted the importance of receiving support from staff during mental health crisis. Although at time point one only $67 \%$ of participants felt that they knew who to contact during a crisis (Item 11), this rose to $78 \%$ of participants at time point two. At time point one only $55 \%$ of participants reported being satisfied with the level of support that their family has been offered (Item 13), but this was not reflected as a theme or sub-theme in the interview data. Of note, satisfaction with family support rose to $71 \%$ of participants at time point two.

The importance of receiving information about the service was noted in the qualitative data. Within this, participants spoke about the importance of receiving valid, transparent information about their diagnosis. However, on the ESQ at time point one, only $57 \%$ of participants felt that they received enough information about their condition and how to cope with it (Item 12). Information about treatment was also noted as important in the qualitative data, with participants highlighting the importance of the availability of information. In support, on the ESQ at time point one only $69 \%$ of participants felt that they had been provided with enough information about the help available from the service (Item 5).

In reference to 'personhood', participants completing the interviews noted the importance of being understood by staff. There was an emphasis on wanting the service to 
understand their situation and how to approach them. On the ESQ at time point one, $79 \%$ of participants felt that their views and worries are taken seriously (Item 2). Although at time point one only $69 \%$ felt that the staff at the service understood their condition and how to help them (Item 4), this rose to $80 \%$ at time point two. Similarly, $69 \%$ of participants at time point one suggested that they were satisfied that their personal, religious and cultural needs were acknowledged (Item 3), compared to $79 \%$ at time point two.

Under the 'personhood' theme, participants highlighted that being treated with respect was important. More specifically, participants felt that staff should be respectful in their interactions and that their wishes should be listened to and accounted for. On the ESQ at time point one, $88 \%$ of participants reported that they are listened to and treated with respect by the people that they see at the service (Item 1), rising to $91 \%$ at time point two. Under the choice sub-theme participants noted the importance of choice about treatment, with an absence of pressure from the service. On the ESQ at time point one, $84 \%$ of participants reported that their appointments were at a time convenient to them (Item 8) and 78\% reported that they were involved in decisions regarding their care (Item 6). Satisfaction with being involved in decisions rose to $83 \%$ at time point two.

The findings from the quantitative data from time point one and the qualitative data were used to make recommendations for service development (see Table 5). Whilst these are devised from the findings of this study, it is hoped that they will be useful for the development of other youth mental health services.

[Table 5 here]

For the Norfolk youth service the recommendations were presented to the team in a single training session, prior to the collection of data for time point two. The 
recommendations were used to discuss and inform clinical practice and improve services. For example, building on previous research (Hodgekins et al., 2017) the service developed and clarified pathways to improve access to appropriate care. As noted, there was a significant improvement in satisfaction scores between the two time points (for the six items of the ESQ measured at both points). Although it cannot be certain that it was the only factor involved, it is possible that the changes made led to improvements in service delivery and subsequently an increase in service user satisfaction scores.

In accordance with existing literature this study highlights the importance of support, information, choice, respect, staff qualities and skills and communication (Lavis and Hewson, 2011; Plaistow et al., 2014, Collins et al, 2017). Plaistow et al. (2014) highlight that lack of continuity of care is a negative factor in service provision for young people. In support, this study demonstrates the importance of knowing who to contact in a crisis. Plaistow et al (2014) also found that medicalisation of difficulties is a negative factor in service user experience. In the current study participants expressed a wish to receive information about their diagnosis and medication but did not share specific views on the models used to inform their care. Factors including stigma and welcoming environments (Lavis and Hewson, 2011; Plaistow et al., 2014) were not identified as themes or sub-themes in the current study. In reference to Plaistow et al's (2014) suggestion that self-reliance is important to service users, participants in this study noted the usefulness of receiving support from staff and peers. The data highlight a preference for being able to access support when needed, suggesting a need for balance between offering independence and being active in service user care.

There are several limitations to this study. Firstly, the ESQ was modified by the Norfolk youth service and two different versions were used. Only identical items were compared meaning that it was not possible to investigate improvements in items that were only included in the first or second versions. Furthermore, psychometric data are not 
available for the ESQs meaning that it is unclear as to whether the questionnaires used were reliable and valid measures of service user experience. It is also possible that service users who were not engaged with the service did not complete the ESQ, resulting in missing and biased data. It should be considered that those engaged with the service might have been more positive in their responses, given that they continued to engage with the service.

The inclusion of between-group analyses was a strength of this study. However, the use of non-parametric statistics should be noted. Although the inclusion of those who were engaged with the service and those who were not engaged might have resulted in a more representative sample, all participants were White British, potentially limiting generalisability of the findings. Also, a small sample was used for the qualitative element of the study. It is possible that this did not fully represent the youth population or those participants providing quantitative data via the ESQ. Some of the themes and subthemes were aligned to the questions used in the interview. Although participants were encouraged to speak about their experiences freely, some elements of the interview might have been leading. It is also possible that views and experiences that might have been important to the participants were not identified and discussed. Finally, the use of face-to-face interviews may have led to social desirability bias.

Youth mental health services are undergoing continued development and further research may be required to influence service design and delivery. For quantitative analysis it might be useful to analyse data and monitor service improvement over time. It might also be interesting to investigate the effect of age, gender, ethnicity and outcome on service user experience. Missing data might be avoided by specifically sampling service users who are known to have disengaged from services. For qualitative analysis it would be interesting to invite service users to attend focus groups to gain their views about services whilst in discussion with each other. This study did not include the youth council in analysis of the 
qualitative data. Future research may benefit from involving service users or 'experts by experience' in data analysis, especially where qualitative approaches are used. Given that the participants included in this study highlighted the importance of family support, it might also be worthwhile investigating carer and family member views of services.

The current study provides important information in light of an international drive to improve mental health services for young people. As youth services develop it will be important to continue asking young people to provide views on their experience of services. Although this study refers to the Norfolk youth service the findings and recommendations are likely to be relevant to the development of other youth mental health services.

${ }^{[1]}$ Although the Norfolk youth service only accepts referrals for people up to 25 years of age, some service users continue to receive treatment beyond 25 years whilst transitioning to adult services. 


\section{References}

Attride-Stirling, J., (2003), 'Development of methods to capture users' views of child and adolescent mental health services in clinical governance reviews (Project evaluation report)", available at:

https://www.corc.uk.net/media/1215/chi_projectevaluationreport.pdf (accessed 15 June 2018).

Braun, V. and Clarke, V. (2006), "Using thematic analysis in psychology", Qualitative Research in Psychology, Vol. 3 No. 2, pp.77-101.

Broad, K. L., Sandhu, V. K., Sanderji, N., and Charach, A. (2017), "Youth experiences of transition from child mental health services from adult mental health services: a qualitative thematic synthesis", BMC Psychiatry, Vol. 17, pp. 1-11.

Coughlan, H., Cannon, M., Shiers, D., Power, P., Barry, C., Bates, T., Birchwood, M., Buckley, S., Chambers, D., Davidson, S. and Duffy, M., Blánaid, G., Healy, C., Healy, C., Keeley, H., Maher, M., Tanti, C. and McGorry, P. (2013), “Towards a new paradigm of care: the International Declaration on Youth Mental Health", Early Intervention in Psychiatry, Vol. 7 No. 2, pp. 103-108.

Collins, R., Notley, C., Clarke, T., Wilson, J. and Fowler, D. (2017). Participation in developing youth mental health services: "Cinderella service" to service re-design, Journal of Public Mental Health, Vol. 16 No. 4, pp. 159-168.

Creswell, J. W. and Plano Clark, V. L. (2011), "Designing and conducting mixed methods research", Sage Publications, Thousand Oaks. 
Department of Health (2015), "Future in mind: promoting, protecting and improving our children and young people's mental health and wellbeing", available at: www.gov.uk (accessed 20 April 2018).

Department of Health and Department of Education (2017), "Transforming children and young people's mental health provision: a green paper", available at: $\underline{\text { www.gov.uk }}$ (accessed 26 November 2019).

Gibb, S. J., Fergusson, D. M. and Horwood, L. J. (2010), "Burden of psychiatric disorder in young adulthood and life outcomes at age 30”, British Journal of Psychiatry, Vol. 197 No. 2, pp. 122-127.

Gorter, J. W., Stewart, D., Woodbury Smith, M., King, G., Wright, M., Nguyen, T., Freeman, M. and Swinton, M. (2014), "Pathways towards positive psychosocial outcomes and mental health for youth with disabilities: a knowledge synthesis of developmental trajectories", Canadian Journal of Community Mental Health, Vol. 33 No. 1, pp. 4561.

Hetrick, S. E., Bailey, A. P., Smith, K. E., Malla, A., Mathias, S., Singh, S. P., O’Reilly, A., Verma, S. K., Benoit, L., Fleming, T. M., Moro, M. R., Richwood, D. J., Duffy, J., Eriksen, T., Illback, R., Fisher, C. A., McGorry, P. D. (2017), “Integrated one-stop shop youth health care: best available evidence and future directions", Medical Journal of Australia, Vol. 207 No. 10, pp. 5-18.

Hodgekins, J., Clarke, T., Cole, H., Markides, C., Ugochukwu, U., Cairns, P., Lower, R., Fowler, D. and Wilson, J. (2017), "Pathways to care of young people accessing a pilot specialist youth mental health service in Norfolk, United Kingdom”, Early Intervention in Psychiatry, Vol. 11 No. 5, pp. 436-443. 
Illback, R.J. and Bates, T. (2011), “Transforming youth mental health services and supports in Ireland", Early Intervention in Psychiatry, Vol. 5, pp. 22-27.

Institute for Innovation and Improvement (2010), “The Handbook of Quality and Service Development Improvement Tools", available at: http://www.miltonkeynesccg.nhs.uk (accessed 21 April 2018).

Kessler, R.C., Angermeyer, M., Anthony, J.C., De Graaf, R.O.N., Demyttenaere, K., Gasquet, I., De Girolamo, G., Gluzman, S., Gureje, O.Y.E., Haro, J.M. and Kawakami, N. (2007), "Lifetime prevalence and age-of-onset distributions of mental disorders in the World Health Organization's World Mental Health Survey Initiative”, World Psychiatry, Vol. 6 No. 3, pp. 168-176.

Lavis, P. and Hewson, L. (2011), "How many times do we have to tell you? A briefing from the National Advisory Council about what young people think about mental health and mental health services", available at: www.chimat.org.uk/resource/item.aspx?RID=110049 (accessed 15 June 2018).

McGorry, P.D. (2007), “The specialist youth mental health model: strengthening the weakest link in the public mental health system", Medical Journal of Australia, Vol. 187 No 7 , pp. S53-S56.

McGorry, P., Trethowan, J. and Rickwood, D. (2019), “Creating headspace for integrated youth mental health care", World Psychiatry, Vol. 18 No. 2, pp.140-141.

McGorry, P., Bates, T. and Birchwood, M. (2013), "Designing youth mental health services for the 21st century: examples from Australia, Ireland and the UK". The British Journal of Psychiatry, Vol. 202 no. 54, pp. s30-s35.

National Health Service England (2015), "Local transformation plans for children and young people's mental health and wellbeing", available at: www.england.nhs.uk (accessed 26 November 2019). 
National Health Service England (2019), “The NHS Long Term Plan”, available at: www.longtermplan.nhs.uk (accessed 26 November 2019).

Palinkas, L. A. (2014), “Qualitative methods in mental health services research”, Journal of Clinical Child and Adolescent Psychology, Vol. 43 No. 6, pp. 851-861.

Plaistow, J., Masson, K., Koch, D., Wilson, J., Stark, R.M., Jones, P.B. and Lennox, B.R. (2014), "Young people's views of UK mental health services", Early Intervention in Psychiatry, Vol. 8 No. 1, pp. 12-23.

Rickwood, D., Van Dyke, N. and Telford, N. (2015), "Innovation in youth mental health services in Australia: common characteristics across the first headspace centres", Early Intervention in Psychiatry, Vol. 9 No. 1, pp. 29-37.

Rickwood, D., Paraskakis, M., Quin, D., Hobbs, N., Ryall, V., Trethowan, J. and McGorry, P. (2019), “Australia's innovation in youth mental health care: The headspace centre model, Early Intervention in Psychiatry, Vol. 13 No. 1, pp. 159-166.

Simmons, M.B., Parker, A.G., Hetrick, S.E., Telford, N., Bailey, A. and Rickwood, D. (2014), "Development of a satisfaction scale for young people attending youth mental health services", Early Intervention in Psychiatry, Vol. 8 No. 4, pp. 382-386.

Singh, S.P., Paul, M., Ford, T., Kramer, T., Weaver, T., McLaren, S., Hovish, K., Islam, Z., Belling, R. and White, S. (2010), "Process, outcome and experience of transition from child to adult mental healthcare: multiperspective study", The British Journal of Psychiatry, Vol. 197 No. 4, pp. 305-312.

Stiles, W. (1993), "Quality control in qualitative research”, Clinical Psychology Review, Vol. 13, pp. 593-618.

Tashakkori, A. and Teddlie, C. (2003), "Handbook of mixed methods in social and behavioural research", Sage Publications, Thousand Oaks. 
Wilson, J., Clarke, T., Lower, R., Ugochukwu, U., Maxwell, S., Hodgekins, J., Wheeler, K., Goff, A., Mack, R., Horne, R. and Fowler, D. (2017), “Creating an innovative youth mental health service in the United Kingdom: The Norfolk Youth Service", Early Intervention in Psychiatry, Vol. 12 No. 4, pp. 740-746. 


\section{Acknowledgements}

The authors would like to thank the participants who took part in this study. They would also like to thank members of the Norfolk youth service council who provided guidance on the content and structure of the semi-structured interview. 
Figure 1

Themes and sub-themes for the thematic analysis

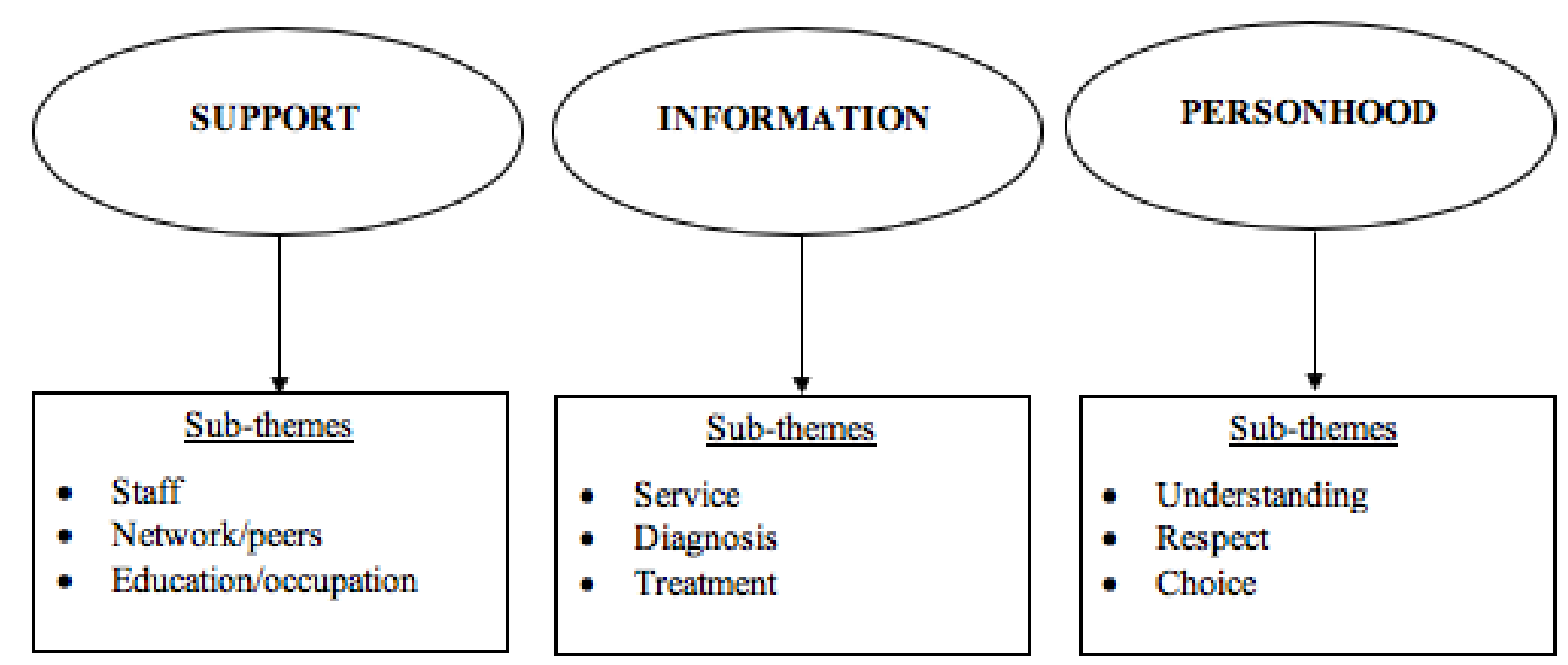

Note. 'Personhood' refers to being treated as an individual. 
Table 1

Demographic information for the sample completing the qualitative element of the study

\begin{tabular}{|c|c|}
\hline Demographic & Number of participants (\%) \\
\hline \multicolumn{2}{|l|}{ Gender } \\
\hline Male & $2(33)$ \\
\hline Female & $4(67)$ \\
\hline \multicolumn{2}{|l|}{ Ethnicity } \\
\hline White British & $6(100)$ \\
\hline \multicolumn{2}{|l|}{ Education status } \\
\hline Full-time & $3(50)$ \\
\hline Part-time & $3(50)$ \\
\hline \multicolumn{2}{|l|}{ Employment status } \\
\hline Full-time & $3(50)$ \\
\hline Part-time & $3(50)$ \\
\hline \multicolumn{2}{|l|}{ Marital status } \\
\hline Single & $6(100)$ \\
\hline \multicolumn{2}{|l|}{ Diagnosis $^{[1]}$} \\
\hline Anxiety & $3(50)$ \\
\hline Obsessions and compulsions & $1(17)$ \\
\hline Depression/mood disorder & $5(83)$ \\
\hline Problems with eating/body weight & $1(17)$ \\
\hline Attentional problems & $1(17)$ \\
\hline Personality difficulties & $2(33)$ \\
\hline
\end{tabular}

${ }^{[1]}$ Five participants had more than one diagnosis and this is reflected in the frequency and percentages stated; percentages are rounded to the nearest whole number. 
Table 2

Quantitative analysis for the ESQ during time point one (Questions 1-13)

\section{Question}

Frequency $(\%)^{[1]}$

1) Ifeel that I am listened to and treated with respect by the people who see me

'Agree' or 'Strongly agree'

Neither agree or disagree

'Disagree' or 'Strongly disagree'

2) My views and worries are taken seriously

'Agree' or 'Strongly agree'

Neither agree or disagree

'Disagree' or 'Strongly disagree'

3) My personal, religious and cultural needs have been

acknowledged

'Agree' or 'Strongly agree'

Neither agree or disagree

'Disagree' or 'Strongly disagree'

4) Ifeel the people here understand my problem and know how to help me

'Agree' or 'Strongly agree'

Neither agree or disagree

'Disagree' or 'Strongly disagree'

5) I have been given enough explanation about the help available from the youth team and elsewhere in the area

'Agree' or 'Strongly agree'

Neither agree or disagree

'Disagree' or 'Strongly disagree'

6) I have been fully involved in decisions regarding my care

'Agree' or 'Strongly agree'

Neither agree or disagree

'Disagree' or 'Strongly disagree'

7) Ifeel that the people who see me are working together to help me

'Agree' or 'Strongly agree'

Neither agree or disagree

'Disagree' or 'Strongly disagree'

8) My appointments are usually at a convenient time

'Agree' or 'Strongly agree'

Neither agree or disagree

'Disagree' or 'Strongly disagree'

9) It is quite easy to get to the place where the appointments are

'Agree' or 'Strongly agree'

Neither agree or disagree

'Disagree' or 'Strongly disagree'

10) The facilities here are comfortable (e.g. waiting room,

consultation room)

'Agree' or 'Strongly agree' 
11) I know who to contact in a crisis

'Agree' or 'Strongly agree'

Neither agree or disagree

'Disagree' or 'Strongly disagree'

12) I have been given enough information about my problem and how to tackle it

'Agree' or 'Strongly agree'

Neither agree or disagree

'Disagree' or 'Strongly disagree'

13) I am satisfied with the level of support that my family has been offered

'Agree' or 'Strongly agree'

Neither agree or disagree

'Disagree' or 'Strongly disagree'

$28(23)$

${ }^{[1]}$ Percentage values are rounded to the nearest whole number 
Table 3

Quantitative analysis for the ESQ for time point two (using the six unchanged questions for comparison)

\section{Question}

Frequency $(\%)^{[1]}$

1) I feel that I am listened to and treated with respect by the people who see me

'Agree' or 'Strongly agree'

Neither agree or disagree

'Disagree' or 'Strongly disagree'

3) My personal, religious and cultural needs have been acknowledged

'Agree' or 'Strongly agree'

Neither agree or disagree

'Disagree' or 'Strongly disagree'

4) I feel the people here understand my problem and know how to help me

'Agree' or 'Strongly agree'

Neither agree or disagree

'Disagree' or 'Strongly disagree'

6) I have been fully involved in decisions regarding my care

'Agree' or 'Strongly agree'

Neither agree or disagree

'Disagree' or 'Strongly disagree'

11) I know who to contact in a crisis

'Agree' or 'Strongly agree'

Neither agree or disagree

'Disagree' or 'Strongly disagree'

13) I am satisfied with the level of support that my family has been offered

'Agree' or 'Strongly agree'

Neither agree or disagree

'Disagree' or 'Strongly disagree'

${ }^{[1]}$ Percentage values are rounded to the nearest whole number 
Table 4

Descriptive statistics and results of Mann Whitney U test comparing ESQ question responses between time point one and two ${ }^{[1]}$

\begin{tabular}{|c|c|c|c|c|c|c|c|}
\hline & \multicolumn{2}{|c|}{ Time point one } & \multicolumn{2}{|c|}{ Time point two } & \multirow{2}{*}{\multicolumn{3}{|c|}{ Mann Whitney U test }} \\
\hline & $\mathbf{N}$ & Mean (SD) & $\mathbf{N}$ & Mean (SD) & & & \\
\hline $\begin{array}{l}\text { I feel that I am listened } \\
\text { to and treated with } \\
\text { respect by the people } \\
\text { who see me }\end{array}$ & 125 & $4.31(.92)$ & 124 & $4.65(.69)$ & $\mathrm{U}=6028.5$ & $\mathrm{z}=-3.55$ & $\mathrm{p}<.001$ \\
\hline $\begin{array}{l}\text { My personal, religious } \\
\text { and cultural needs have } \\
\text { been acknowledged }\end{array}$ & 125 & $3.96(.89)$ & 111 & $4.37(0.86)$ & $\mathrm{U}=5096.5$ & $z=-3.77$ & $\begin{array}{c}\mathrm{p}< \\
.0013\end{array}$ \\
\hline $\begin{array}{l}\text { Ifeel the people here } \\
\text { understand my problem } \\
\text { and know how to help } \\
\text { me }\end{array}$ & 125 & $3.82(1.17)$ & 124 & $4.29(1.02)$ & $\mathrm{U}=5828$ & $z=-3.62$ & $\mathrm{p}<.001$ \\
\hline $\begin{array}{l}\text { I have been fully } \\
\text { involved in decisions } \\
\text { regarding my care }\end{array}$ & 125 & $4(1.15)$ & 121 & $4.38(.92)$ & $\mathrm{U}=6049.5$ & $z=-2.96$ & $\mathrm{p}=.003$ \\
\hline $\begin{array}{l}\text { I know who to contact } \\
\text { in a crisis }\end{array}$ & 125 & $3.61(1.21)$ & 122 & $4.23(1.13)$ & $\mathrm{U}=5054$ & $z=-4.83$ & $\mathrm{p}<.001$ \\
\hline $\begin{array}{l}\text { I am satisfied with the } \\
\text { level of support that my } \\
\text { family has been offered }\end{array}$ & 125 & $3.47(1.25)$ & 117 & $4.11(1.06)$ & $\mathrm{U}=5139.5$ & $\mathrm{z}=-4.16$ & $\mathrm{p}<.001$ \\
\hline
\end{tabular}

${ }^{[1]}$ Bonferroni correction was made for multiple testing, significance value adjusted to $p=.008$ 
Table 5

Recommendations for youth mental health service development

\begin{tabular}{|c|c|}
\hline Theme & Recommendation \\
\hline Support & $\begin{array}{l}\text { - Staff members should be proactive and available } \\
\text { - Provide practical and moral support where needed } \\
\text { - Ensure that service users receive enough support } \\
\text { - Regularly check that service users feel supported } \\
\text { - Support should be offered to service users' family members } \\
\text { - Provide support with education, including communication with teachers } \\
\text { - } \text { and other professionals } \\
\text { - } \text { educational issues } \\
\text { - } \text { Provide support with occupation } \\
\text { - } \text { Prolp to build service user confidence to prepare them for occupation } \\
\text { - (e.g. social groups) or online (e.g. social media) } \\
\text { together }\end{array}$ \\
\hline Information & $\begin{array}{l}\text { - Service users should be made aware of the service } \\
\text { - Service users should be provided with information about the service } \\
\text { - Provide information in the form of a website or leaflet } \\
\text { - Service users should be provided with information about who they can } \\
\text { - } \text { contact in crisis } \\
\text { - } \text { Informoses should be identified where appropriate } \\
\text { - Service users should receive a diagnosis if helpful to them } \\
\text { - Diagnoses should be shared with and explained to service users } \\
\text { - Information about available treatments should be provided } \\
\text { - Leaflets explaining treatments should be available to service users }\end{array}$ \\
\hline Personhood & $\begin{array}{l}\text { - Treat service users as individuals } \\
\text { - Staff members should understand the service users' situation, including } \\
\text { their diagnosis/symptoms and personal history } \\
\text { - Staff should be respectful in interactions with service users } \\
\text { - Staff should maintain service user confidentiality } \\
\text { - Service users' needs and wishes should be listened to and accounted for } \\
\text { - Service users should be offered choice in whether their treatment is } \\
\text { - Shared with family members } \\
\text { - Service users should be involved in decisions about treatment } \\
\text { - Service users should not feel obliged to receive certain treatments }\end{array}$ \\
\hline
\end{tabular}

